\title{
ВЛИЯНИЕ МИКРОБИОЛОГИЧЕСКОГО ПРЕПАРАТА «БАЙКАЛ-ЭМ1» НА FOLSOMІА CANDIDA (WILLEM, 1902) (HEXAPODA, COLLEMBOLA)
}

N.P. Kazakova

\section{THE INFLUENCE OF MICROBIOLOGICAL PREPARATION «BAIKAL-EM1» ON FOLSOMIA CANDIDA (WILLEM, 1902) (HEXAPODA, COLLEMBOLA)}

Казакова Наталья Павловна - канд. биол. наук, доц. каф. биологии Хакасского государственного университета им. Н.Ф.Катанова, г. Абакан. E-mail: goloshapova07@mail.ru

В статье приводятся данные результатов экспериментального исследования воздействия микробиологического препарата «БайкалЭM1» на Folsomia candida (Willem, 1902) (Hexapoda, Collembola). Задачи - оценка влияния «Байкал-ЭМ 1» на следующие показатели: кратность увеличения численности особей ногохвосток в культуре; время появления первых кладок и количество яии в них; выживаемость яии, ювенилов и взрослых особей в культуре; некоторые количественные показатели роста ювенильных особей; типичные формы поведения коллембол исследуемого вида. Экспериментальным путем установлено положительное влияние микробиологического nрепарата «Байкал-ЭМ1» на репродуктивные возможности ногохвосток. Отмечено, что использование F. candida в пищу колоний микроорганизмов, выращенных на основе препарата «Байкал-ЭМ1», способствовало улучшению показателей их яйцепродукции, сокращению сроков появления первых яйцекладок и созревания яиц. Отрицательного воздействия «Байкал-ЭМ1» на рост и жизнеспособность ювенильных и взрослых особей в ходе эксперимента установлено не было. Во всех вариантах опыта выживаемость яии, ювенилов и взрослых особей составляла $100 \%$. Негативного влияния исследуемого препарата на темп и характер популяционного роста ногохвосток в культуре выявлено не было. Кратность увеличения культуры коллембол была примерно в 0,8 раза выше в варианте с использованием «Байкал-ЭМ1». Применение пре-
Kazakova Natalya Pavlovna - Cand. Biol. Sci., Assoc. Prof., Chair of Biology, N.F. Katanov Khakass State University, Abakan.

E-mail: goloshapova07@mail.ru

парата «Байкал-ЭМ1» не отразилось на протекании типичных форм поведения особей F. candida. Таким образом, использование микробиологического препарата «Байкал-ЭМ1», вероятно, оказывает положительное влияние на выживаемость и потенциал репродукции коллембол и определяет их более высокую эф-фоективность в процессах почвообразования.

Ключевые слова: активизаторы почвенного плодородия, микробиологические удобрения, ЭМ-технология, микробиологический препарат «Байкал ЭМ-1», почвенное плодородие, Folsomia candida.

The data of experimental research of the effect of microbiological preparation "Baikal-EM1" on Folsomia candida (Willem, 1902) (Hexapoda, Collembola) were given in the study. The objective was to assess the impact of Baikal-EM1 on the following indicators: the multiplicity of increase in the number of individuals of Collembola in cultivation, the time of emergence of the first laying and the amount of eggs in them, the survival rate of eggs, juvenile and adult individuals in cultivation, some quantitative indices of juvenile individuals growth; typical forms of Collembola behavior of spring tails of studied species. Positive influence of microbiological preparation "Baikal-EM1" on reproductive opportunities of Collembola was experimentally established. It was noted that using $F$. candida in food colonies of microorganisms grown on the basis of the preparation"Baikal-EM1" contributed to the improvement of their egg production, reducing the timing of the appearance of the first oviposition 
and egg maturation. Negative impact of "BaikalEM1" on the growth and viability of juvenile and adult individuals was not found out during the experiment. In all the variants of the experiment survival rate of eggs, juveniles and adults made $100 \%$. There was no negative influence of studied preparation on the rate and nature of population growth in cultivation. Frequency rate of increase in culture Collembola was about 0.8 times higher than in the option with using "Baikal-EM1". The preparation "Baikal-EM1" did not influence the course of typical forms of behavior of $F$. candida individuals. So, using microbiological preparation "Baikal-EM1" probably has a positive impact on the survival and reproduction potential of Collembola and determines their higher efficiency in the processes of soil formation.

Keywords: activators of soil fertility, microbiological fertilizers, EM-technology, microbiological preparation "Baikal-EM1", soil fertility, Folsomia candida.

Введение. Одним из современных развивающихся направлений в аграрном производстве является разработка и использование технологий и методик на основе эфффективных микроорганизмов (ЭМ-технология). ЭМ-препараты обладают ценными свойствами для поддержания почвенного плодородия, активизации роста и развития растений и педобионтов [1]. Считается, что ЭМ-препараты способны активизировать почвенную биоту, обеспечивать оптимальные экологические условия для поддержания плодородия почв, ускорять процессы разложения органических веществ в почве и существенно улучшать условия питания растений $[2,3]$. Микробиологические удобрения по многим показателям в несколько раз превосходят органические удобрения. Основные из них: наличие активной микрофллоры, стойкость к вымыванию из почвы питательных элементов, максимальное сохранение и накопление азота, отсутствие семян сорняков, патогенной микрофрлоры, яиц гельминтов.

В настоящее время ЭМ-технология нашла свое применение в разных областях жизнедеятельности человека: в растениеводстве, цветоводстве, грибоводстве, животноводстве, почвоведении, пищевой промышленности, комму- нальном хозяйстве, быту, охране окружающей среды [4]. Особое внимание уделяется ЭМпрепаратам в связи с возможностью их использования для решения проблем загрязнения окружающей среды путем устранения негативных последствий индустриализации естественными методами. В частности, обоснована целесообразность применения ЭМ-препаратов («БайкалЭМ 1», «Восток», «Тамир») при биологической рекультивации почв, загрязненных углеводородами нефти и нефтепродуктов [5]. На примере угольных разрезов Красноярского края доказана высокая эфффективность ЭМ-технологии в формировании почвенно-растительного покрова на техногенно нарушенных территориях [6].

Почвенная фрауна - один из самых важных факторов почвообразования, влияющих на все свойства почвы, включая ее плодородие. Деятельность педобионтов сводится к повышению пористости почвы, водо- и воздухопроницаемости, ускорению гумификации и минерализации растительных остатков, изменению солевого режима и реакции почвы. Огромное значение для процессов почвообразования имеет деятельность почвенных животных, которая способствует углублению гумусового горизонта и перемешиванию слоев почвы, а также создает водопрочную зернистую структуру. Использование микробных препаратов вполне благоприятным образом сказывается на педобионтах, так как не приводит к нарушениям состава и активности сложившегося в пахотной почве комплекса беспозвоночных - почвообразователей и повышает общую численность почвенных животных [1].

Детальные исследования по оценке влияния ЭМ-препаратов на некоторые особенности биологии и экологии микроартропод не проводились, хотя именно эти педобионты оказывают существенное влияние на интенсивность процессов биологического разложения органических веществ, определяющих восстановление плодородия почв. Коллемболы являются многочисленной и разнообразной группой почвенных микроартропод, распространенной во всех типах природных и антропогенных почв [7]. Функциональная роль ногохвосток в почвенных биоценозах связана с их трофической деятельностью, поскольку они являются активными по- 
требителями микрофрлоры, почвенного детрита, грибного мицелия, бактериальных пленок, а также утилизаторами и переработчиками растительного опада. Кроме того, коллемболы могут быть использованы для сравнительного анализа естественных экосистем и агроценозов с целью разработки экологически безопасных технологий в сельском хозяйстве [8].

Цель исследования. Экспериментальная оценка влияния микробиологического препарата «Байкал-ЭМ 1» на Folsomia candida (Willem 1902) (Hexapoda, Collembola).

Задачи исследования: оценка влияния «Байкал-ЭМ1» на кратность увеличения численности культуры ногохвосток F. candida; время появления первых кладок и количество яиц в них; выживаемость яиц, ювенилов и взрослых особей в культуре; количественные показатели роста ювенильных особей; типичные формы поведения коллембол исследуемого вида.

Методы исследования. В лабораторных условиях наблюдали за культурой коллембол, содержащейся на «Байкал-ЭМ-1». Микробиологический препарат «Байкал-ЭМ1» изготовлен ООО «НПО ЭМ-Центр» (Россия, номер гос. регистрации 226-19.156-1). Для наблюдений был выбран верхнеподстилочный с чертами троглобионта вид ногохвосток Folsomia candida Willem, так как он является вполне удобным объектом при проведении лабораторных экспериментов (способен к партеногенезу, хорошо размножается в лабораторных условиях, имеет высокую скорость оборота популяций) [9]. F. candida довольно многочисленный вид в антропогенных местообитаниях. Встречается в закрытых грунтах в южных районах России, регистрируется в агроценозах, в компостах, на отвалах [10].

Ногохвосток содержали в соответствии со стандартными методиками группового культивирования. Особей коллембол размещали в стеклянных камерах, в затемнении, при комнатной температуре $\left(23-25^{\circ} \mathrm{C}\right)$ на увлажненной гипсово-угольной смеси в соотношении 9:1. Высота камер составляла 5,5 см, диаметр окружности субстрата, на котором непосредственно размещались коллемболы, - 2 см. Сверху экспериментальные камеры были прикрыты стеклянными пластинками, через которые вели наблюдение с помощью микроскопа Альтами СМ0745. Исходно ногохвосток рассаживали в лабораторные камеры с помощью эксгаустера из расчета 10 одновозрастных половозрелых особей (с длиной тела 1,5-1,6 мм) на камеру. Всего было сформировано 20 камер, из которых 10 являлись контрольными.

В качестве корма ногохвосткам, содержавшимся в экспериментальных камерах, были предложены колонии микроорганизмов, выращенные на питательной среде (агар-агар) с использованием микробиологического препарата «Байкал-ЭМ1». В контрольных камерах ногохвосток кормили сухими пекарскими дрожжами. Во все камеры корм раскладывали порционно, размером примерно по 3 мм², в центре, на субстрат. Увлажнение, проветривание камер и смену корма в них проводили ежедневно. Приготовление рабочего раствора препарата «Байкал-ЭМ1» осуществляли в соответствии с рекомендациями производителя, в концентрации 1:100 (10 мл препарата в 1 литре дистиллированной воды). Показатели размножения и развития особей $F$. candida оценивали начиная со второй генерации, родительские особи которой в контрольном варианте содержались исключительно на «Байкал-ЭМ1». Измерение длины тела ногохвосток проводили под микроскопом с использованием окуляр-микрометра.

Результаты исследования и их обсуждение. Во всех вариантах эксперимента в лабораторных камерах у особей $F$. candida отмечали наличие групповых кладок яиц. В варианте C применением «Байкал-ЭМ1» особи коллембол производили первые кладки в среднем на 1,4 дня раньше, чем в контрольных вариантах. Количество яиц в кладках в контрольных камерах составляло от 117 до 207 яиц, в экспериментальных - от 178 до 265. На одну особь в среднем приходилось 22,5 $\pm 1,0$ яйца в эксперимен-

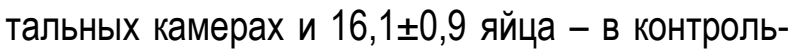
ных (при р=0,95) (табл.). 


\section{Показатели размножения и развития особей Folsomia candida при их содержании на «Байкал-ЭМ1»}

\begin{tabular}{|l|c|c|}
\hline \multicolumn{1}{|c|}{ Показатель } & $\begin{array}{c}\text { «Байкал-ЭМ1» } \\
\text { (n=10 камер) }\end{array}$ & $\begin{array}{c}\text { Контроль } \\
\text { (n=10 камер) }\end{array}$ \\
\hline $\begin{array}{l}\text { Время до появления первых } \\
\text { кладок, дни }\end{array}$ & $9,3 \pm 0,2$ & $10,7 \pm 0,2$ \\
\hline $\begin{array}{l}\text { Среднее кол-во яиц в камере } \\
\text { на одну особь }\end{array}$ & $22,5 \pm 1,0$ & $16,1 \pm 0,9$ \\
\hline Сроки развития яиц, дни & $5,7 \pm 0,2$ & $7,9 \pm 0,2$ \\
\hline Выход молоди, \% & $100 \%$ & $100 \%$ \\
\hline
\end{tabular}

Развитие яиц ногохвосток протекало без каких-либо внешних аномальных изменений. По мере созревания яйца F. candida увеличивались в размере, приобретали по сравнению с исходными несколько овальную форму и более темную окраску. Выход молоди из яиц во всех камерах составлял $100 \%$, был отмечен в экспериментальных камерах на 5,7士0,2-й день, в контрольных - на 7,9 $\pm 0,2-и ̆$ день $(p=0,95)$. Гибели ювенильных особей не наблюдалось ни в одном из вариантов опыта.

Количественная оценка изменения длины тела особей (мм) с момента их выхода из яиц и в течение 31-34 дней не выявила существенной разницы по этому показателю как в контрольных, так и в экспериментальных вариантах опыта. В первый день выхода ювенильных особей из яиц длина их тела составила примерно 0,2 мм во всех сериях эксперимента (рис.). В дальнейшем для ногохвосток был характерен линейный рост тела и к 31-34-му дню с момента их выхода из яиц длина тела была около 0,9 мм. К 60-62-му дню наблюдений длина тела особей достигла своего предельного значения и составила 1,5 мм [10].

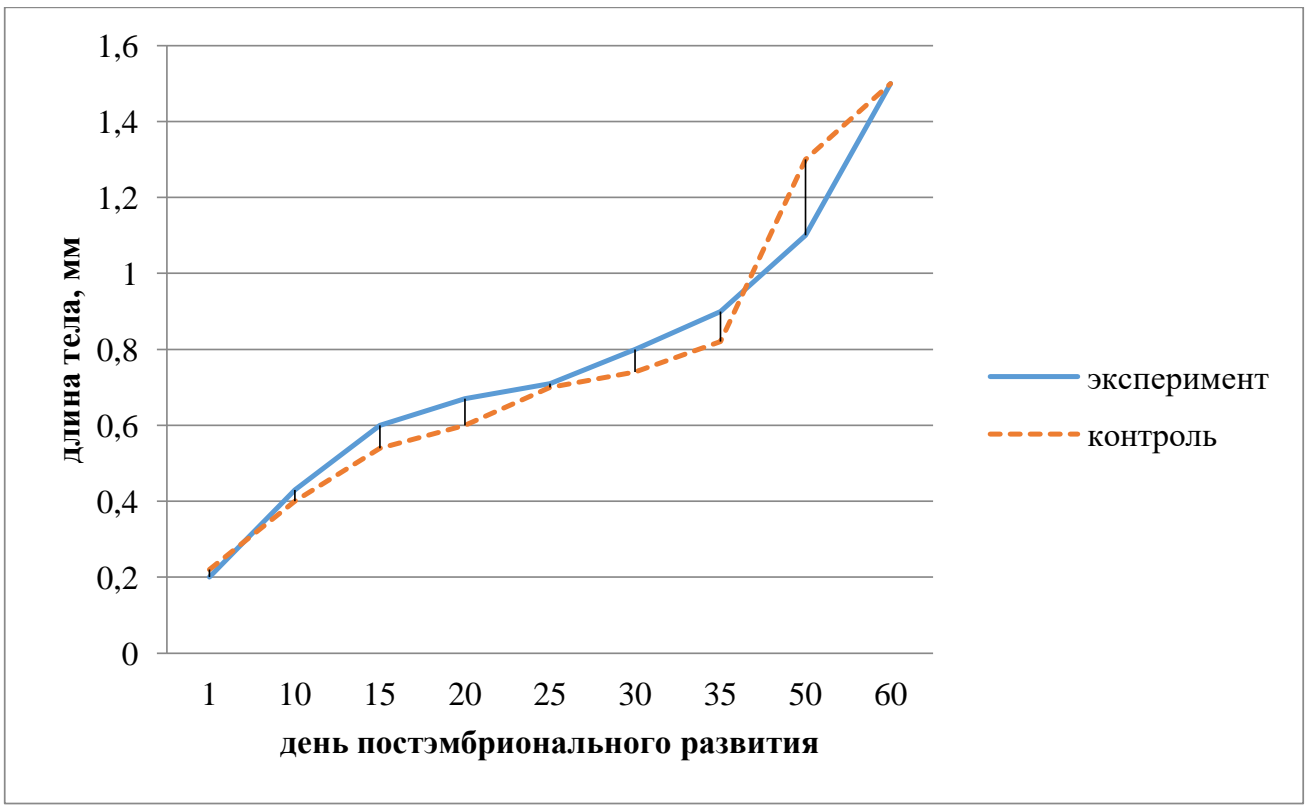

Показатели роста длины тела Folsomia candida

В ходе последующих наблюдений особи F. candida продолжали откладывать яйца, что приводило к росту их численности в культуре. На 25-й день с момента размещения особей в камеры ими были произведены еще яйцекладки. К 31-34-му дню от начала эксперимента численность особей в культуре увеличилась (примерно в 16 раз в контроле, и примерно в 
20 раз - в опыте). В результате суммарный объем культуры в контрольном варианте составил примерно 170 особей и 323 яйца, в эксперименте - примерно 230 особей и 549 яиц. Проведение дальнейших микроскопических наблюдений за ногохвостками не представлялось возможным из-за сложности подсчета особей в многочисленной культуре и искажения результатов эксперимента по причине действием механизмов, сдерживающих рост плотности популяции (агрессивное поведение особей, каннибализм) [11]. В целом исследуемые особи коллембол сохраняли жизнеспособность и размножались в течение длительного времени.

Сравнение основных фрорм поведения, свойственных особям $F$. candida, в контроле и эксперименте существенных различий не выявило. Не было замечено каких-либо отклонений от нормы в типичных формах поведения особей исследуемого вида, ранее описанных в литературе [10, 12]. Во всех вариантах особи F. candida, независимо от возраста, претерпевали линьки, чистки, которые протекали у них стандартно. Уровень двигательной активности особей был типичным и сохранял свойственный для данного вида характер.

Выводы. В условиях эксперимента нами не было установлено отрицательного воздействия препарата «Байкал-ЭМ1» на рост и жизнеспособность отдельных особей $F$. candida. Также не было выявлено негативного влияния на темп и характер популяционного роста ногохвосток в культуре. Во всех вариантах опыта отмечалась 100\%-я выживаемость яиц, ювенилов и взрослых особей. Кратность увеличения численности коллембол в культуре была в 0,8 раза выше в варианте с применением «Байкал-ЭМ1», так как препарат, вероятно, оказывал положительное воздействие на репродуктивные возможности $F$. candida. На типичных формах поведения ногохвосток действие препарата «Байкал-ЭМ1» не отразилось.

Таким образом, использование ЭМтехнологий, в частности микробиологического препарата «Байкал ЭМ-1», вероятно, может оказывать положительное влияние на жизнеспособность и успешность размножения коллембол и тем самым определять их более высокую эффективность в процессах почвообразования.

\section{Литература}

1. Симонович Е.И. Перспективы изучения применения биологических активизаторов почвенного плодородия как способа экологизации земледелия // Фундаментальные исследования. - 2014. - № 9. - С. 24812484.

2. Кураченко Н.Л., Халипский А.Н., Казанов В.В. Влияние микробиологического удобрения «Азофит»» на агрофизическое состояние чернозема и продуктивность рапса, возделываемого на маслосемена // Вестник КрасГАУ. - 2019. - № 3. - С. 22-28.

3. Новицкий А.А., Гнитецкий В.А. ЭМ-технология в растениеводстве // Вестник Омского государственного аграрного университета. - 2012. - № 4 (8). - C. 20-24.

4. Аллахвердиев С.Р., Ерошенко В.И. Современные технологии в органическом земледелии // Международный журнал прикладных и фундаментальных исследований. 2017. - № 1. - С. 76-79.

5. Чачина С.Б., Верба Е.Ю. Биологическая рекультивация почв, загрязненных мазутом, с использованием вермикультуры дождевых червей Dendrobaena veneta и микробиологических препаратов «Байкал-ЭМ», «Тамир», «Восток» // Экология и строительСтво. - 2018. - № 3. - С. 27-35.

6. Новицкий А.А., Плешакова В.И., Конина А.А. [и др.]. ЭМ-технология на фоне мировой практики // Электронный научно-методический журнал Омского ГАУ. - 2015. - № 1 (1). - С. 1-10.

7. Кузнецова Н.А. Организация сообществ почвообитающих коллембол. - М.: Прометей, 2005. - 243 c.

8. Овчинникова Ю.Ю., Старостенко Е.В., Штири А.Д. Ногохвостки (Collembola) как биоиндикаторы антропогенной трансформации экосистем // Біорізноманіття та роль тварин в екосистемах: матеріали IV Міжнародної наукової конференції. - Днїпропетровськ: Вид-во ДНУ, 2007. - С. 206-208.

9. Usber M.B., Stoneman C.F. Folsomia candida - an ideal organism for population studies in the laboratory // J. Biol. Ed. -1977. - № 11. P. 83-90. 
10. Чернова Н.М., Голощапова Н.П., Потапов М.Б. Поведение близких видов коллембол семейства Isotomidae // Зоологический журнал. - 2003. - Т. 82. - № 10. - С.11911200.

11. Чернова Н.М., Авилкина А.Т. Поведение разных видов ногохвосток (Collembola) при возрастании плотности популяции // Зоологический журнал. - 2003. - Т.82. - № 2. C. 248-255.

12. Авилкина А.Т., Чернова Н.М. Особенности поведения коллембол разных жизненных форм // Зоологический журнал. - 2001. T. 80. - № 9. - C.1074-1075.

\section{Literatura}

1. Simonovich E.I. Perspektivy izucheniya primeneniya biologicheskih aktivizatorov pochvennogo plodorodiya kak sposoba ekologizacii zemledeliya // Fundamental'nye issledovaniya. - 2014. - № 9. - S. 24812484.

2. Kurachenko N.L., Halipskij A.N., Kazanov V.V. Vliyanie mikrobiologicheskogo udobreniya «Azofit» na agrofizicheskoe sostoyanie chernozema i produktivnost' rapsa, vozdelyvaemogo na maslosemena // Vestnik KrasGAU. - 2019. - № 3. - S. 22-28.

3. Novickij A.A., Gniteckij V.A. EM-tekhnologiya v rastenievodstve // Vestnik Omskogo gosudarstvennogo agrarnogo universiteta. - 2012. № 4 (8). - S. 20-24.

4. Allahverdiev S.R., Eroshenko V.I. Sovremennye tekhnologii $v$ organicheskom zemledelii // Mezhdunarodnyj zhurnal prikladnyh i fundamental'nyh issledovanij. - 2017. - № 1. - S. 76-79.
5. Chachina S.B., Verba E.Yu. Biologicheskaya rekul'tivaciya pochv, zagryaznennyh mazutom, $s$ ispol'zovaniem vermikul'tury dozhdevyh chervej Dendrobaena veneta i mikrobiologicheskih preparatov «Bajkal-EM», «Tamir», «Vostok» // Ekologiya i stroitel'stvo. - 2018. № 3. - S. 27-35.

6. Novickij A.A., Pleshakova V.I., Konina A.A. [i dr.]. EM-tekhnologiya na fone mirovoj praktiki // Elektronnyj nauchno-metodicheskij zhurnal Omskogo GAU. - 2015. - № 1 (1). - S. 1-10.

7. Kuznecova N.A. Organizaciya soobshchestv pochvoobitayushchih kollembol. - M.: Prometej, 2005. - $243 \mathrm{~s}$.

8. Ovchinnikova Yu.Yu., Starostenko E.V., Shtirc A.D. Nogohvostki (Collembola) kak bioindikatory antropogennoj transformacii ekosistem // Biopiznomanittya ta rol' tvarin v ekosistemah: materiali IV Mizhnarodnoï naukovoï konferenciï. - Dnïpropetrovs'k: Vid-vo DNU, 2007. - S. 206-208.

9. Usber M.B., Stoneman C.F. Folsomia candida - an ideal organism for population studies in the laboratory // J. Biol. Ed. -1977. - № 11. P. 83-90.

10. Chernova N.M., Goloshchapova N.P., Potapov M.B. Povedenie blizkih vidov kollembol semejstva Isotomidae // Zoologicheskij zhurnal. - 2003. - T. 82. - № 10. - S.11911200.

11. Chernova N.M., Avilkina A.T. Povedenie raznyh vidov nogohvostok (Collembola) pri vozrastanii plotnosti populyacii // Zoologicheskij zhurnal. - 2003. - T.82. - № 2. S. 248-255.

12. Avilkina A.T., Chernova N.M. Osobennosti povedeniya kollembol raznyh zhiznennyh form // Zoologicheskij zhurnal. - 2001. - T. 80. № 9. - S.1074-1075. 